\title{
Meiosis in Three Species of Heteroptera from Ethiopia (East Africa)
}

\author{
Harbhajan Kaur* and Bezuayehu Kerisew Semahagn \\ Department of Zoology, Punjabi University, Patiala 147 002, Punjab, India
}

Received November 23, 2009; accepted March 20, 2010

\begin{abstract}
Summary Regardless of rich biodiversity, cytogenetic work on African Heteroptera is meagre. This paper reports meiotic behaviour of chromosomes in 3 species of Heteroptera from Ethiopia for the first time. Paracritheus trimaculatus and Eurydema pulchrum, both belonging to Pentatomidae, possess $2 n=14=12 \mathrm{~A}+\mathrm{XY}$ while Cletus punctulatus belonging to Coreidae possesses $2 n=18=$ $14 \mathrm{~A}+2 \mathrm{~m}+\mathrm{X}_{1} \mathrm{X}_{2} 0$. Certain characteristics are common in the 2 species of Pentatomidae such as fusion of the $\mathrm{X}$ and $\mathrm{Y}$ to form a heteropycnotic body at diffuse stage, and their behaviour at diakinesis and metaphase II. The 2 species, however, differ in chiasma frequency, the pattern of chromosomes at metaphase $\mathrm{I}$ and the degree of association between $\mathrm{X}$ and $\mathrm{Y}$ in the pseudobivalent at metaphase II. In Cletus punctulatus, the 2 sex chromosomes, $\mathrm{X}_{1}$ and $\mathrm{X}_{2}$, remain fused throughout meiosis except for a brief period during metaphase I. The fused $\mathrm{X}$ chromosomes precedes the autosomes during anaphase II. The Chiasma frequency is seen to be higher.
\end{abstract}

Key words Meiosis, Chromosomes, Heteroptera, Pentatomidae, Coriedae.

Cytogenetically, members of the sub-order Heteroptera are characterized by possessing holocentric chromosomes (Buck 1968, Comings and Okada 1972, González-García et al. 1996, Perez et al. 1997, 2000) and inverted meiosis for sex chromosomes in which they divide equationally during first meiotic division and reductionally during second meiotic division (Ueshima 1979, Nokkala and Nokkala 1984, Camacho et al. 1985, Rebagliati et al. 2005). Besides, many heteropteran species possess a pair of minute chromosomes (m-chromosomes) with special meiotic behaviour (Ueshima 1979, Grozeva and Nokkala 1996). One of the largest families within Heteroptera is Pentatomidae, which includes 4112 species distributed in 8 sub-families: Asopinae, Cyrtocorinae, Discocephalinae, Edessinae, Pentatominae, Phyllocephalinae, Podopinae and Serbaninae, and most of them are economically important phytophagous species (Schuh and Slater 1995). Karyologically, most of the pentatomid species present a diploid number of $14(2 n=$ $12 \mathrm{~A}+\mathrm{XX} / \mathrm{XY}$ ) with no m-chromosomes and this chromosome number has been considered to be the type number of the family (Manna 1951, White 1973, Ueshima 1979, Muramoto 1981, Nuamah 1982, Dey and Wangdi 1985, Satapathy and Patnaik 1988, Rebagliati et al. 2005). The family Coreidae, which includes 2200 species belonging to 500 genera throughout the world, has a very wide distributional range (Dolling 2006). The modal diploid chromosome number of the family Coreidae is considered to be $2 n=21$ with the presence of a pair of m-chromosomes and an $\mathrm{XO} / \mathrm{XX}$ sex determining system (Franco et al. 2006).

Regardless of this rich biodiversity, cytogenetic work on African Heteroptera is meagre. Only a handful studies from Ghana and South Africa have been released for the scientific world (Kumar 1971, Nuamah 1982, Jacobs and Liebenberg 2001, Jacobs 2002b, 2003a, b, 2004, Jacobs and Groneveld 2002). Studies pertaining to behaviour of chromosomes during meiosis of 3 heteropteran species from Ethiopia (East Africa) have been done for the first time. Two of the species viz. Paracritheus trimaculatus and Eurydema pulchrum belong to Pentatomidae while the other, Cletus

\footnotetext{
*Corresponding author, e-mail: harbhajankaur@hotmail.com
} 
punctulatus, belongs to Coreidae. Karyological studies on Eurydema pulchrum from India and Japan and Cletus punctulatus from India have earlier been carried out (Manna 1962, Ueshima 1979, Kaur et al. 2006). In the present paper, karyological details of Ethiopian Eurydema pulchrum and Cletus punctulatus have been compared with those of Indian species. Cytogenetic details of Paracritheus trimaculatus are discussed for the first time.

\section{Materials and methods}

Adult males of 2 species of Pentatomidae, Paracritheus trimaculatus Lepeletier and Serville and Eurydema pulchrum Westwood, and 1 species of Coreidae, Cletus punctulatus Westwood, were collected from surrounding areas of Debre Markos (North-eastern Ethiopia) located at $10^{\circ} 30^{\prime} \mathrm{N}$ $37^{\circ} 73^{\prime} \mathrm{E}$ coordinates. All the specimens were collected from Cicer arietinum (Leguminosae). Testes were extracted and fixed in $3: 1$, ethyl alcohol : glacial acetic acid. Slides were prepared by the airdried technique and then were stained in Carbol-fuchsin.

\section{Results}

\section{Paracritheus trimaculatus}

The diploid chromosome complement of Paracritheus trimaculatus is $2 n=14=12 \mathrm{~A}+\mathrm{XY}$. At the diffuse stage, a single darkly stained heteropycnotic body representing the fused $\mathrm{X}$ and $\mathrm{Y}$ is found at the periphery of the nucleus while the autosomes appear as diffused chromatin (Fig. 1A). The paired $\mathrm{X}$ and $\mathrm{Y}$ chromosomes remain almost fused during diplotene (Fig. 1B) but by diakinesis, they get separated so that 6 autosomal bivalents and 2 sex univalents are clearly observable. Each autosomal bivalent shows a single terminal chiasma. Both $\mathrm{X}$ and $\mathrm{Y}$ appear bipartite and are lightly stained as compared to the bivalents. One of the autosomal bivalents is distinctly larger; 4 are medium-sized while 1 is distinctly smaller in size. The $\mathrm{X}$ chromosome is almost equal to the smallest autosome while $\mathrm{Y}$ is the smallest element of the complement (Fig. 1C). Metaphase I is characterized by 6 axially oriented chromosomes forming a ring that includes 5 autosomal bivalents and the $\mathrm{X}$ chromosome while the largest autosomal bivalent and the $\mathrm{Y}$ chromosome lie inside near the inner border of the ring. The bipartite nature of the sex chromosomes is maintained during metaphase I (Fig. 1D). At metaphase II, autosomes form a ring while $\mathrm{X}$ and $\mathrm{Y}$ that join terminally to form a pseudobivalent, lie in the centre of the ring (Fig. 1E).

\section{Eurydema pulchrum}

Eurydema pulchrum possesses a male diploid chromosome number of $14=12 \mathrm{~A}+\mathrm{XY}$. At the diffuse stage, the $\mathrm{X}$ and $\mathrm{Y}$ are fused to form a darkly stained heteropycnotic body that lies against decondensed autosomes (Fig. 2A). During diplotene, 6 autosomal bivalents and 2 sex chromosomes become distinct. One of the autosomal bivalents is slightly larger, 4 are of medium size while 1 is slightly smaller in size. One of the medium sized bivalents shows 2 terminal chiasmata while the rest possess only 1 terminal chiasma each (Fig. 2B). By diakinesis, the ringed bivalent loses 1 of the terminal chiasmata. The bipartite nature of the sex chromosomes becomes distinct (Fig. 2C). During metaphase I, the autosomal bivalents and sex chromosomes are not arranged in a regular pattern (Fig. 3D-E). At metaphase II, however, a regular arrangement is seen with autosomal bivalents forming a ring at the centre of which lie 2 sex chromosomes, $\mathrm{X}$ and $\mathrm{Y}$, which appear aligned opposite to each other but terminal association between them is lacking (Fig. 2F).

\section{Cletus punctulatus}

Cletus punctulatus possesses a diploid complement of 18 chromosomes $\left(14 \mathrm{~A}+2 \mathrm{~m}+\mathrm{X}_{1} \mathrm{X}_{2} 0\right)$. During diffuse stage, 2 distinctly unequal $\mathrm{X}$ chromosomes, $\mathrm{X}_{1}$ and $\mathrm{X}_{2}$ associate together to form a 

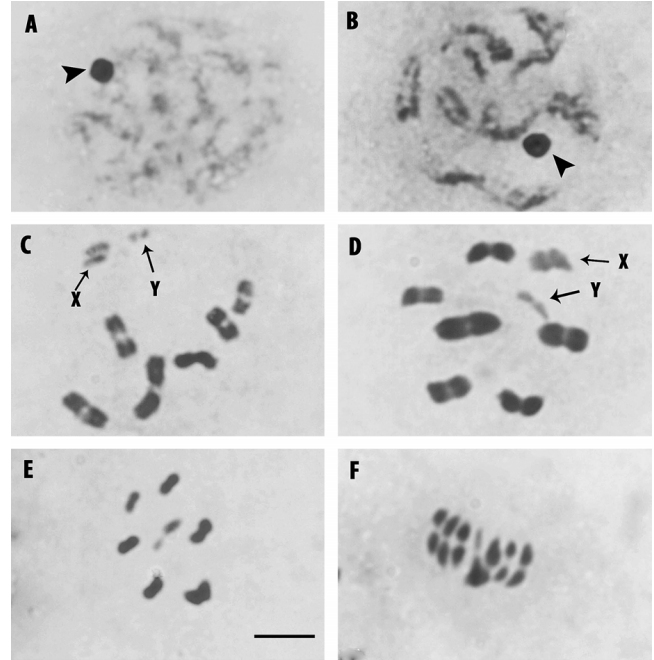

Fig. 1. Paracritheus trimaculatus. (A) Diffuse stage showing fused X and Y (arrowheads). (B) Early diplotene. (C) Diakinesis. (D) Metaphase I. (E) Metaphase II. (F) Anaphase II. Scale bar $=10$ $\mu \mathrm{m}$.
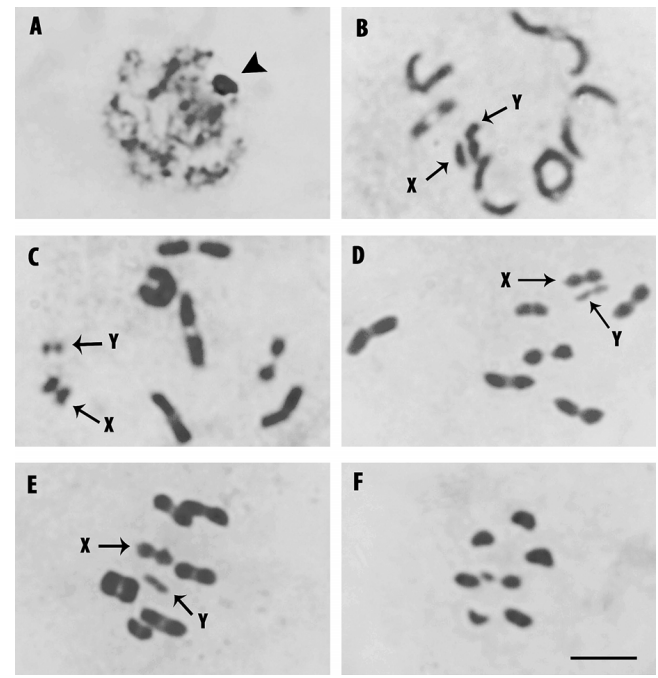

Fig. 2. Eurydema pulchrum. (A) Diffuse stage showing fused X and Y (arrowheads). (B) Diplotene. (C) Diakinesis. (D,E) Metaphase I with irregularly arranged chromosomes. (F) Metaphase II showing a ring of autosomal univalents with weakly associated sex chromosomes. Scale bar= $10 \mu \mathrm{m}$.
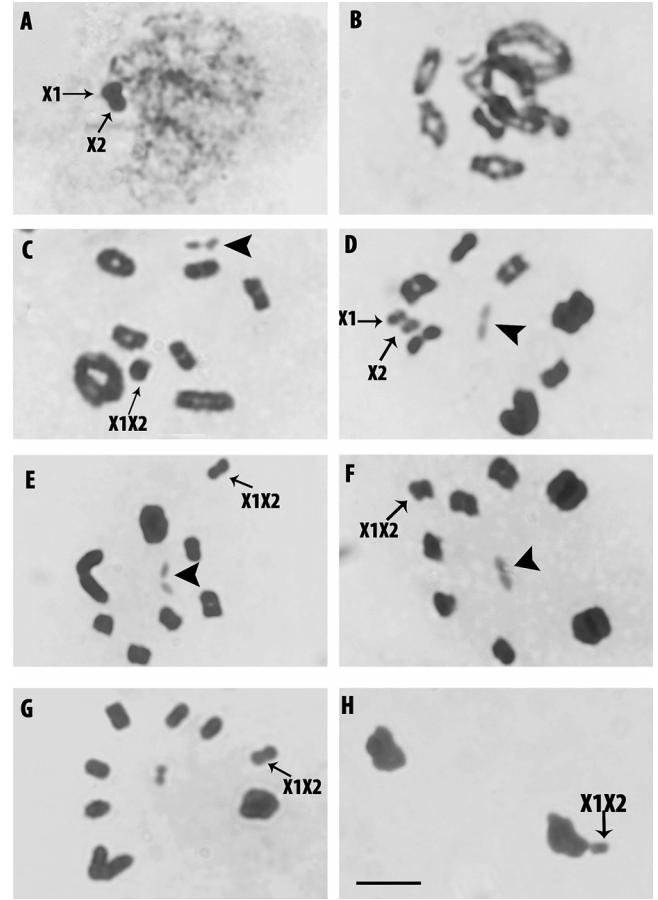

Fig. 3. Cletus punctulatus. (A) Diffuse stage showing closely associated unequal $\mathrm{X}_{1}$ and $\mathrm{X}_{2}$. (B) Diplotene. (C) Diakinesis. (D-F) Metaphase I stages showing three different positions of the $\mathrm{X}_{1} \mathrm{X}_{2}$ body. (G) Metaphase II. (H) Telophase II, one with $\mathrm{X}_{1} \mathrm{X}_{2}$ and the other without it. Arrowheads point to the $\mathrm{m}$ chromosome pair. Scale bar $=10 \mu \mathrm{m}$.

single hetropycnotic body which lies very close to the nuclear membrane (Fig. 3A). At diplotene, 7 autosomal bivalents, 2 fused sex chromosomes $\mathrm{X}_{1} \mathrm{X}_{2}$ and 2 microchromosomes ( $\mathrm{m}$-chromosomes) are clearly visible. The $\mathrm{m}$ chromosomes are associated terminally to form the achiasmatic bivalent. On the basis of size, the bivalents can be classified into 3 groups. Two autosomal bivalents are distinctly larger, 5 are of medium size while the $\mathrm{m}$ bivalent is the smallest in the complement. The $\mathrm{X}_{1}$ and $\mathrm{X}_{2}$ are smaller than the medium sized autosomes and can be distinguished from the autosomes due to their heteropycnotic nature. The 2 largest autosomal bivalents show 2 terminal chiasmata and appear as ring bivalents while the rest of the bivalents show single terminal/subterminal chiasma (Fig. 3B). In most of the diakinesis plates, only 1 ringed 
bivalent is seen. The sex chromosomes still appear fused (Fig. 3C). The first division metaphase plate consists of a ring of 7 autosomal bivalents with the m-chromosome pair at the centre. $\mathrm{X}_{1}$ and $\mathrm{X}_{2}$ get separated but are closely placed. Their position on the plate is variable. In some plates, they lie on the periphery of the ring along with autosomal bivalents; in others, they lie just on the outer border of the ring, while in still others they lie far away from the ring. In some of the plates, size difference between $\mathrm{X}_{1}$ and $\mathrm{X}_{2}$ is clearly visualized (Fig. 3D-F). At metaphase II, all the autosomes form a ring with the $\mathrm{m}$-chromosome lying in the centre. The fused $\mathrm{X}_{1} \mathrm{X}_{2}$ body lies outside the ring (Fig. 3G). Two types of Telophase II plates are seen, one with $7 \mathrm{~A}+\mathrm{m}+\mathrm{X}_{1} \mathrm{X}_{2}$ while the other with $7 \mathrm{~A}+\mathrm{m}+0$. In $7 \mathrm{~A}+\mathrm{m}+\mathrm{X}_{1} \mathrm{X}_{2}$ plates, the fused sex chromosome body lies outside the autosomal group (Fig. 3H).

\section{Discussion}

Both Paracritheus trimaculatus and Eurydema pulchrum (Pentatomidae) show a diploid chromosome number of $14=12 \mathrm{~A}+\mathrm{XY}$ which agrees with earlier reports for this family as the modal number (Manna 1951, Ueshima 1979, Muramoto 1981, Nuamah 1982, Dey and Wangdi 1985, Sathapathy and Patnaik 1988). Hetropterans are characterized by a peculiar diffuse stage during which synapsed autosomal bivalents undergo decondensation while sex chromosomes remain condensed and heteropycnotic. The degree of chromosome decondensation has been found to be variable among different species. In the present study, the extent of decondensation has been found to be very high in Paracritheus trimaculatus as has earlier been seen in most of the Heteroptera species by Solari (1979), Nokkala and Nokkala (1984), Camacho et al. (1985), Nokkala (1986), Rebagliati et al. (1998) and Lanzone and Souza (2006) whereas in Eurydema pulchrum, decondensation is only partial as is observed so far only in few species such as Acanonicus hahni and Adamanotus uncotibialis by Papeschi and Mola (1990) and Jacobs and Liebenberg (2001) respectively.

The $\mathrm{X}$ and $\mathrm{Y}$ chromosomes continue to remain fused throughout diplotene and separate at diakinesis in Paracritheus trimaculatus as is also observed in Agoroscelis nublis (Manna 1951), Dinocoris prolineatus (Rebagliati et al. 2001) and Antiteuchus mixus (Lanzone and Souza 2006). In Eurydema pulchrum, however, $\mathrm{X}$ and $\mathrm{Y}$ separate at diplotene. In heteropterans, there is predominance of 1 chiasma per bivalent (Satapathy and Patnaik 1988, González-García et al. 1996, Grozeva and Nokkala 1996, Bressa et al. 1999, Nokkala and Nokkala 1999, Lanzone and Souza 2006). In Paracritheus trimaculatus also, a single chiasma per bivalent is observed. In Eurydema pulchrum, however, 1 medium sized bivalent is always seen with 2 terminal chiasmata. Camacho et al. (1985), Mola and Papeschi (1993) and Rebagliati et al. (2001) also observed bivalents with 2 chiasmata. Generally, the ring bivalent is formed by the largest autosomal pair.

In most of the pentatomid species, Metaphase I is characterized by a ring of autosomal bivalents at the centre of which lie the X and Y uinvalents (Manna 1951, Satapathy and Patnaik 1988, Rebagliati et al. 2001, Lanzone and Souza 2006). Eurydema pulchrum lacks this typical arrangement of chromosomes at metaphase I plate where the chromosomes are distributed randomly as is also observed in this species from India (Kaur et al. 2006) and in Coridius obscures and Carbula biguttata (Satapathy and Patnaik 1988). In Paracritheus trimaculatus, chromosomes behave differently in forming the metaphase I plate. The largest autosomal bivalent and the Y chromosome lie mostly inside the ring which is formed by 5 autosomal bivalents and the $\mathrm{X}$ chromosome. This behaviour is less common in Pentatomidae and is recorded only in Agonoscelis nubila, Eysarcoris guttiger and Carbula socia (Satapathy and Patnaik 1988).

The end-to-end association of X and Y chromosomes in the pseudobivalent during metaphase II is evident in both Paracritheus trimaculatus and Eurydema pulchrum. However, the degree of association is stronger in Paracritheus trimaculatus than Eurydema pulchrum. At metaphase II, 
autosomes form a ring inside which lies the pseudobivalent XY, an arrangement seen in other pentatomid species also (Manna 1951, Parshad 1957b, Satapathy and Patnaik 1988, Rebagliati et al. 2001). The condition, however, differs in Indian Eurydema pulchrum in which autosomes and the pseudobivalent form the ring while centre of the ring is occupied by the largest autosome (Kaur et al. 2006).

So far, 5 species of Cletus, viz. Cletus trigonus, Cletus punctulatus, Cletus bipunctatus, Cletus pugnator and Cletus sp., have been cytologically investigated and the most common diploid number is $2 n=18=14 \mathrm{~A}+2 \mathrm{~m}+\mathrm{X}_{1} \mathrm{X}_{2} 0$ (Manna 1951, Parshad 1957d). However, Parshad (1957d) and Kaur et al. (2006) reported $2 n=17=14 \mathrm{~A}+2 \mathrm{~m}+\mathrm{X} 0$ and $2 n=19=16 \mathrm{~A}+2 \mathrm{~m}+\mathrm{X} 0$ in Cletus sp. and Cletus bipunctatus respectively. The $\mathrm{X}_{1}$ and $\mathrm{X}_{2}$ are fused at diffuse stage and remain so throughout diplotene and diakinesis and get separated at metaphase I. Here it is possible to differentiate the 2 on the basis of size, 1 being slightly smaller than the other. Parshad (1957d), however, failed to see any size difference between $\mathrm{X}_{1}$ and $\mathrm{X}_{2}$ in specimens of Cletus punctulatus collected from India. Size difference is earlier reported in Cletus bipunctatus by Manna (1951).

The 2 largest autosomal bivalents exist as ring bivalents in most of the early diplotene plates with a mean chiasma frequency of 8.4 per complement. At diakinesis, either one or both of the chiasmata get terminalized with a mean chiasma frequency reduced to 7.5 per complement. On the other hand, in Indian Cletus punctulatus, 1 ring bivalent has been observed only occasionally at diplotene (mean chiasma frequency=7.1 per complement) by Parshad (1957d). In Cletus bipunctatus, chiasma frequency has been found to vary between 7 and 9 per nucleus (Manna 1951).

In all the species of Cletus studied so far, a definite arrangement pattern is observed at metaphase I in which the autosomal bivalents form a ring, m-bivalent lies in the centre while the sex chromosomes lie on the outer border of the ring (Manna 1951, Parshad 1957d, Kaur et al. 2006). In Ethiopian Cletus punctulatus also, autosomes always form a ring and the m-bivalent lies in the centre but the positions of $\mathrm{X}_{1}$ and $\mathrm{X}_{2}$ is variable. They are either part of the ring or lie on outer border of the ring or far away from the ring. At metaphase II, autosomes and fused sex chromosomes $\mathrm{X}_{1} \mathrm{X}_{2}$ roughly form a ring and m-chromosome lies in the centre. The formation of an accessory plate by $X_{1} X_{2}$ recorded in this species previously by Parshad (1957d) is not observed in the present study. During anaphase II, $\mathrm{X}_{1} \mathrm{X}_{2}$ precede the autosomes and are clearly seen outside the group of autosomes at telophase II as is earlier observed by Parshad (1957d).

\section{References}

Bressa, M. J., Papeschi, A. G., Mola, L. M. and Larramendy, M. L. 1999. Meiotic studies in Dysdercus Guérin Méneville, 1931 (Heteroptera: Pyrrhocoridae). I. Neo-XY in Dysdercus albofasciatus Berg, 1878, a new sex chromosome determining system in Heteroptera. Chromosome Res. 7: 503-508.

Buck, R. C. 1968. Mitosis and meiosis in Rhodnius prolixus: the fine structure of the spindle and diffuse kinetochore. J. Ultrastruct. Res. 18: 489-501.

Camacho, J. P. M., Belda, J. and Cabrero, J. 1985. Meiotic behaviour of the holocentric chromosomes of Nezara viridula (Insecta, Heteroptera) analysed by C-banding and silver impregnation. Can. J. Genet. Cytol. 27: 490-497.

Comings, D. E. and Okada, T. A. 1972. Holocentric chromosomes in Oncopeltus: kinetochore plates are present in mitosis but absent in meiosis. Chromosoma 37: 177-192.

Dey, S. K. and Wangdi, T. 1985. Meiotic chromosomes and sex mechanism in males of twelve species of Heteroptera. Entomon 10: 327-328.

Dolling, W. R. 2006. Coreidae Leach, 1815. Catalogue of Heteroptera of the Palaearctic Region, Vol. 5, Pentatomomorpha II. The Netherlands Entomological Society, Amsterdam, pp. 43-101.

Franco, M., Bressa, M. J. and Papeschi, A. G. 2006. Karyotype and male meiosis in Spartocera batatas and meiotic behavior of multiple sex chromosomes in Coreidae (Heteroptera). Eur. J. Entomol. 103: 9-16.

González-García, J. M., Antonio, C., Suja, J. A. and Rufas, J. S. 1996. Meiosis in holocentric chromosomes: Kinect activity is ramdoly restricted to the chromatid ends of sex univalents in Graphosoma italicum (Heteroptera). Chromosome Res. 4: 124-132.

Grozeva, S. and Nokkala, S. 1996. Chromosomes and their meiotic behavior in two families of the primitive infraorder 
Dipsocoromorpha (Heteroptera). Hereditas 125: 31-36.

Jacobs, D. H. 2002b. Cytogenetics and karyotype evolution of the genus Miteronotus Jacobs (Heteroptera: Aradidae: Carventinae) with an assessment of the possible role of pseudopolyploidy in their karyotype evolution. African Entomology 10: 171-184.

- 2003a. The behaviour of a multiple sex chromosome system in Dundocoris flavilineatus (Heteroptera: Aradidae: Carventinae) that originated by autosome-sex chromosome fusion. Folia Biologica (Kraków) 51: 23-32.

- 2003b. Cytogenetics of the genus Dundocoris hoberlandt (Heteroptera, Aradidae, Carventinae) where chromosome fusion played the dominant role in karyotype evolution. Caryologia 56: 233-252.

- 2004. The evolution of a neo- $\mathrm{XY}_{1} \mathrm{Y}_{2}$ sex chromosome system by autosome-sex chromosome fusion in Dundocoris nodulicarinus Jacobs (Heteroptera: Aradidae: Carventinae). Chromosome Res. 12: 175-191.

- and Groeneveld, H. T. 2002. Cytogenetics and karyotype evolution of the genus Silvacoris Jacobs (Heteroptera: Aradidae: Carventinae) with the description of a statistical method to compare karyotypes. Cytologia 67: 159-168.

- and Liebenberg, H. 2001. Cytogenetics of Adamanotus uncotibialis Jacobs (Heteroptera: Aradidae). Caryologia 54: 83-96.

Kaur, H., Chhabra, S., Suman, V. and Gupta, M. 2006. Chromosomes and their Meiotic Behavior in Two Families of the Sub-Order Heteroptera. Cytologia 71 (2): 111-118.

Kumar, R. 1971. Chromosomes of Cocoa-Capsids (Heteroptera: Miridae). Caryologia 24: 229-237.

Lanzone, C. and Souza, M. J. 2006. Chromosome complement and meiosis in three species of the Neotropical bug genus Antiteuchus (Heteroptera, Pentatomidae, Discocephalinae). Gen. Mol. Biol. 29: 49-55.

Manna, G. K. 1951. A study of the chromosomes during meiosis in forty three species of Indian Heteroptera. Proc. Zool. Soc. (Bengal) 4: 1-116.

- 1962. A further evaluation of the cytology and inter-relationships between various groups of Heteroptera. Nucleus 5: $7-28$.

Mola, L. M. and Papeschi, A. G. 1993. Meiotic studies in Largus rufipennis (Castelnau) (Largidae, Heteroptera). Frequency and behaviour of ring bivalents, univalents and B chromosomes. Heredity 71: 33-40.

Muramoto, N. 1981. A chromosome study of thirteen species of heteropteran insects (Heteroptera). La Kromosoma 11-23: $668-675$.

Nuamah, K. A. 1982. Karyotypes of some Ghanian shield bugs and the higher systematics of the Pentatomoidea (Hemiptera: Heteroptera). Insect. Sci. Appl. 3: 9-28.

Nokkala, S. 1986. Themechanisms behind the regular segregation of the m-chromosomes in Coreus marginatus L. (Coreidae, Hemiptera). Hereditas 105: 73-85.

— and Nokkala, C. 1984. The occurrence of the XO sex chromosome system in Dictyonota tricornis (Schr.) (Tingidae, Hemiptera) and its significance for concepts of sex chromosome system evolution in Heteroptera. Hereditas 100: 299-301.

— and - 1999. Chromosomes in two bug species of Hebrus (Hebridae, Heteroptera). The occurrence of neo-XY sex chromosome system in Heteroptera. Caryologia 52: 27-30.

Papeschi, A. G. and Mola, L. M. 1990. Meiotic studies in Acanonicus hahni (Stal) (Coreidae, Heteroptera) I. Behaviour of univalents in desynaptic individuals. Genetica 80: 31-38.

Parshad, R. 1957b. Cytological studies in Heteroptera III. A comparative study of the chromosomes in the male germ-cell of eleven species of the sub-family Pentatominae. Res. Bull., Punjab Univ. 122: 401-420.

- 1957d. Cytological studies in Heteroptera IV. Chromosome complement and meiosis in twenty six species of the Pentatomoidea, Lygaeoidea and Coreoidea with a consideration of the cytological bearing on the status of these super families. Res. Bull., Punjab Univ. 133: 521-559.

Perez, R., Panzera, F., Page, J., Suja, J. A. and Rufas, J. S. 1997. Meiotic behaviour of holocentric chromosomes: Orientation and segregation of autosomes in Triatoma infestans (Heteroptera). Chromosome Res. 5: 47-56.

Perez, R., Rufas, J. S., Suja, J. A., Page, J. and Panzera, F. 2000. Meiosis in holocentric chromosomes: Orientation and segregation of an autosome and sex chromosomes in Triatoma infestans (Heteroptera). Chromosome Res. 8: 17-25.

Rebagliati, P. J., Mola, L. M. and Papeschi, A. G. 2001. Karyotype and meiotic behaviour of the holokinetic chromosomes of six Argentine species of Pentatomidae (Heteroptera). Caryologia 54: 339-347.

- , - - - and Grazia, J. 2005. Cytogenetic studies in Pentatomidae (Heteroptera): A review. Blackwell Verlag, Berlin. JZS 43: 199-213.

—, Papeschi, A. G., Mola, L, M., Pietrokovsky, S., Gajate, P., Bottazzi, V. and Wisnivesky-Colli, C.1998. Comparative meiotic studies in Triatoma sordida (Stal) and T. Guasayana Wygodzinsky \& Abalos (Reduviidae, Heteroptera). Mem. Inst. Oswaldo Cruz 93: 309-315.

Satapathy, S. N. and Patnaik, S. C. 1988. Chromosomal studies in seven species of family Pentatomidae (Heteroptera). Caryologia 41: 49-60. 
Schuh, R. T. and Slater, J. A. 1995. True Bugs of the World (Hemiptera; Heteroptera: Classification and Natural History). Cornell University Press, Ithaca, London.

Solari, A. J. 1979. Autosomal synaptonemal complex and sex chromosomes without axes in Triatoma infestans (Reduviidae, Hemiptera). Chromosoma 72: 225-240.

Ueshima, N. 1979. Animal Cytogenetics. v.3. Insecta 6. Hemiptera II: Heteroptera. Gebrüder Borntraeger, Berlin-Stuttgart, pp. 117.

White, M. J. D. 1973. Animal Cytology and Evolution, 3rd ed. Cambridge University Press, London. 